\title{
Hemihypomimia: an atypical and interesting feature of Parkinson's disease
}

\author{
Hemihipomimia: um sinal infrequente e interessante da doença de Parkinson \\ Bárbara Santos PANICHELLI', Mariana SPITZ1
}

Bradykinesia is a key feature of Parkinson's disease (PD) ${ }^{1}$. In contrast to facial bradykinesia, limb bradykinesia is a well described phenomenon. Hypomimia develops in almost all PD patients ${ }^{2}$ as a symmetrical feature. Hemihypomimia is a rare manifestation seen mostly, but not exclusively, on right-sided $\mathrm{PD}^{2}$. We present images of two patients with hemihypomimia (Figure 1).

Understanding the underlying mechanisms of how hemihypomimia develops, and why it predominantly affects the right side of the face deserves further assessment. Larger case series are needed to elucidate the pathophysiology and clinical implications of this interesting feature of PD.
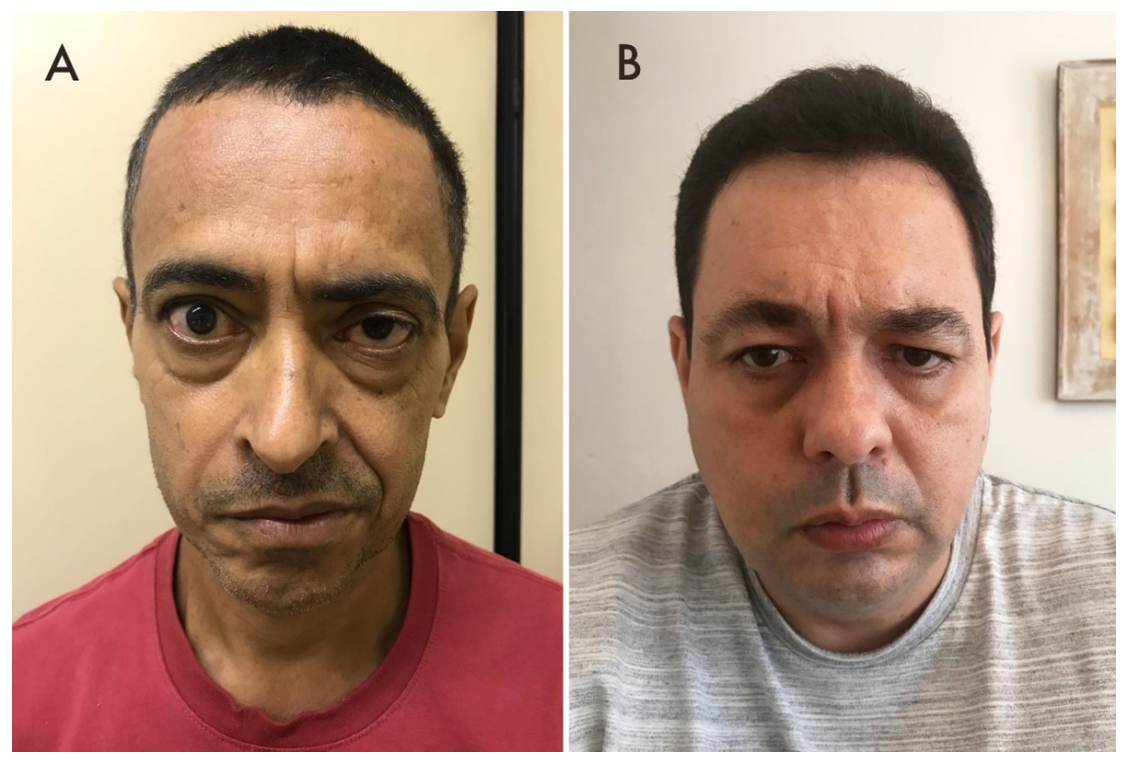

Figure. (A) A 52-year old man, diagnosed to have PD presents marked right-side hypomimia; (B): A 46-year old man diagnosed with PD displaying evident right-sided hypomimia.

\section{REFERENCES}

1. Bologna M, Fabbrini G, Marsili L, Defazio G, Thompson PD, Berardelli

A. Facial bradykinesia. J Neurol Neurosurg Psychiatry. 2013

Jun;84(6):681-5. https://doi.org/10.1136/jnnp-2012-303993
2. Ozekmekçi S, Benbir G, Ozdogan FY, Ertan S, Kiziltan ME.

Hemihypomimia, a rare persistent sign in Parkinson's disease: follow up of 11 patients.J Neurol. 2007 Mar;254(3):347-50.

\footnotetext{
'Universidade do Estado do Rio de Janeiro, Hospital Universitário Pedro Ernesto, Serviço de Neurologia, Rio de Janeiro, RJ, Brazil. Bárbara Santos Panichelli (iD https://orcid.org/0000-0003-1522-8385; Mariana Spitz (D) https://orcid.org/0000-0001-7548-2313 Correspondence: Bárbara Santos Panichelli; E-mail: panichelli.barbara@gmail.com
} Conflict of interest: There is no conflict of interest to declare.

Authors' contribution: BSP: was involved in conceptualization and writing original draft; MS: was involved in conceptualization, writing, review and editing the article.

Received on October 02, 2020; Received in its final form on January 14, 2021; Accepted on February 14, 2021 